\title{
Modeling and simulation of a complex ThermoSysPro model with OpenModelica Dynamic Modeling of a combined cycle power plant
}

\author{
El Hefni Baligh ${ }^{1} \quad$ Bouskela Daniel $^{1}$ \\ ${ }^{1}$ EDF R\&D STEP, Electricité de France, \{baligh.el-hefni, daniel.bouskela\} @edf.fr
}

\begin{abstract}
ThermoSysPro (TSP) is a generic library for the modeling and simulation of power plants and other kinds of energy systems. TSP library is developed by EDF and released under open source license. The library features multi-domain modeling such as thermalhydraulics, neutronics, combustion, solar radiation, instrumentation and control.

Numerous organizations and individuals worldwide now use TSP. Until recently, the TSP library could be used only under Dymola for the modeling and simulation of complex power plants. But now, with the latest version of OpenModelica $(\mathrm{OM})$, we can simulate complex models of power plants with complex scenarios.

To be able to use TSP under OM, some adaptations have been applied to our models, essentially the method used to make inverse computation.

The objective of this work is to evaluate the potentiality, capability and efficiency of using OpenModelica tools to perform dynamic studies of power plants. A combined cycle power plant has been chosen as a representative test case of the complexity of this type of study.

The paper describes the dynamic model of a combined cycle power plant, whose objective is to study a step variation load from $100 \%$ to $50 \%$ and a full gas turbine trip, using OM software. Also, the structure of the model, the parameterization data, the results of simulation runs, the difficulties encountered using OM and the comparison between Dymola and OM are presented.
\end{abstract}

Keywords: Modelica; OpenModelica; ThermoSysPro; thermal-hydraulics; combined cycle power plant; dynamic modeling; inverse problems.

\section{Introduction}

Modeling and simulation play a key role in the design phase and performance optimization of complex energy processes. They also play a significant role in the future for power plant maintenance and operation.
ThermoSysPro is a generic library for the modeling and simulation of power plants and other kinds of energy systems. ThermoSysPro library is developed by EDF and released under open source license.

The foundations of the library are based on first physical principles: mass, energy, and momentum conservation equations, up-to-date pressure losses and heat exchange correlations, and validated fluid properties functions. The correlations account for the non-linear behavior of the phenomena of interest. They cover all water/steam phases, oil, molten salt and all flue gas compositions. The granularity of the modeling may be freely chosen. Some correlations are given by default since they correspond to the most frequent use-cases, but they can be freely modified by the user if needed. This includes the choice of the pressure drop or heat transfer correlations. Special attention is given to the handling of two-phase flow, as two-phase flow is a common phenomenon in power plants.

The library components are written in such a way that there are no hidden or unphysical equations, that components are independent from each other and to ensure as much as possible upward and downward compatibility across tools and library versions. This is particularly important in order to control the impact of component, library or tool modifications on the existing models.

This library is aimed at providing the most frequently used model components for the 0D-1D static and dynamic modeling of thermodynamic systems, mainly for power plants, but also for other types of energy systems such as industrial processes, energy conversion systems, buildings etc. It involves disciplines such as thermal-hydraulics, combustion, neutronics and solar radiation.

The ambition of the library is to cover all the phases of the plant lifecycle, from basic design to plant operation. This includes for instance system sizing, verification and validation of the instrumentation and control system, system diagnostics and plant monitoring. To that end, the library will be linked in the future to systems engineering via the modeling of systems properties, and to the process measurements via data reconciliation and data assimilation. 
The library may be downloaded freely together with the OpenModelica software from

https://openmodelica.org/download/downloadwindows.

Several test-cases were developed to validate the library in order to cover the full spectrum of use-cases for power plant modeling:

- Dynamic model of a 1300 MWe nuclear power plant covering the primary and secondary loops,

- Dynamic model of steam generators for sodium fast reactor (David F., Souyri A. and Marchais G, 2009)

- Static and dynamic models of a biomass plant (El Hefni B. and Péchiné B, 2009),

- Physics/neutronics model in Modelica for a tool, to assist the operator, to control the power plant for infrequent transients and to establish a strategy of optimal operating procedure (El Hefni B., 2011),

- Dynamic model of a concentrated solar power plant (El Hefni B., 2013),

- Dynamic multi-configuration model of a 145 MWe concentrated solar power plant with the ThermoSysPro library (tower receiver, molten salt storage and steam generator)', (El Hefni B., Soler R., 2014),

- Dynamic simulation of a 1MWe CSP tower plant with two-level thermal storage implemented with control system (S.J. Liua et al., 2014),

- Dynamic simulation and experimental validation of Open Air Receiver and Thermal Energy Storage systems in solar thermal power plant (Qing Li et al., 2015).

The objective of this paper is to show the potentiality, capability and efficiency of OpenModelica tools to perform dynamic studies using complex models such as the combined cycle power plant model.

In order to challenge the dynamic simulation capabilities of the library, a step load variation from $100 \%$ to $50 \%$ and a turbine trip (sudden stopping of the gas turbine) were simulated.

\section{How to use OpenModelica for inverse problems (model inversion)}

As the initial state of the simulation is in general defined by the observable outputs of the system (e.g. the nominal power output, the pressure inside the boiler, etc.), it is necessary to solve an inverse problem to compute the initial state. Moreover, it is necessary to start the simulation from a stationary (or steady) state in order to avoid the numerical difficulties which arise when the system is started out of equilibrium (oscillations, stiffness ...).
The inverse problem basically consists in setting (fixing) a state variable of the model to a known measurement value to compute by model inversion the value of a parameter or a boundary condition.

Modelica allows to express inverse problems, which is a powerful feature for computing operation points, which are defined by their observable outputs, and for system sizing, to compute parameterised characteristics.

To implement the inverse problem under Dymola, it is enough simply to fix the value of the state variable and declared it to (fixed $=$ true) and released the parameter to be computed and declared it as (fixed $=$ false). However, this method is incompatible with OpenModelica (no standard Modelica language).

Here is a simple example to illustrate the deference between Dymola and OM for the implementation of the reverse problem (standard Modelica language). Furthermore, for the demonstration we use a simple model to calculate the pressure drop in a tube, so:

$$
P_{i}-P_{o}=K \cdot \frac{Q \cdot|Q|}{\rho}
$$

$P_{i}$ is the fluid pressure at the singularity inlet $(\mathrm{Pa}), P_{o}$ is the fluid pressure at the singularity outlet $(\mathrm{Pa}), Q$ is the fluid mass flow rate $(\mathrm{kg} / \mathrm{s}), K$ is the friction pressure loss coefficient $\left(\mathrm{m}^{-4}\right)$ and $\rho$ is the average density of the fluid $\left(\mathrm{kg} / \mathrm{m}^{3}\right)$.

As the above equation is implemented in a TSP component model called SingularPressureLoss, this model component is used to illustrate inverse calculation. The model uses the following component models (see Figure 1):

- SingularPressureLoss model,

- SourceP model,

- SinkP model.

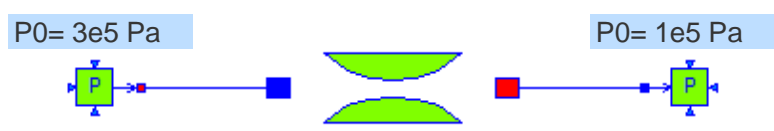

Figure 1. TestSingularPressureLoss model (testcase).

The equation above makes it possible to calculate the flow rate of the fluid through the tube, provided that the pressure drop in the tube, the coefficient of the pressure drop and the fluid density are known (parameters).

The model inversion (calibration) consists in setting the mass flow rate of the fluid through the tube $(\mathrm{Q})$ and the friction pressure loss coefficient of the pipe $(\mathrm{K})$ can be computed. To express this inverse problem with Dymola, it suffices to write: [Q (fixed $=$ true, start $=$ 500)] and [K (fixed=false, start $=100]$ in the parameters 
windows of the SingularPressureLoss model (see Figure 2).

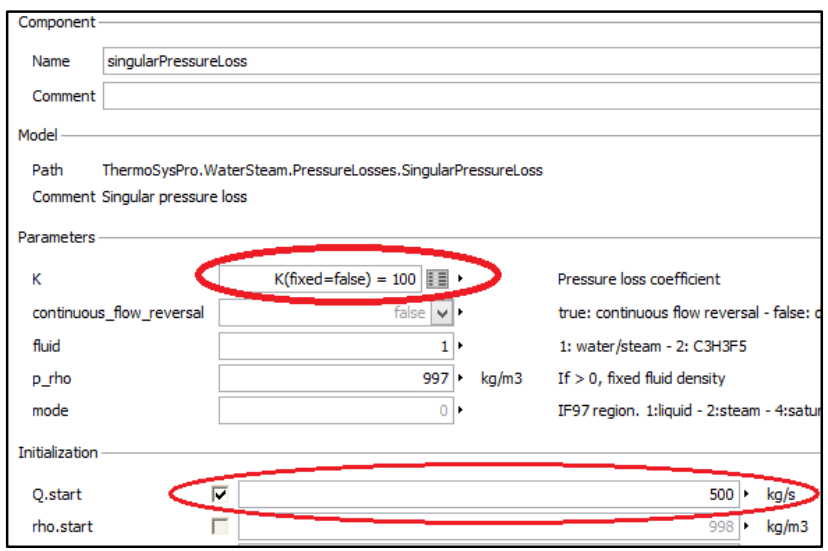

Figure 2. Data for the SingularPressureLoss model.

On the other hand, to express this inverse problem with OpenModelica (also valid for Dymola), it is necessary to write: $\quad[Q$ (fixed $=$ true, start $=500$ ) ] and $\mathbf{K}=\mathbf{K}$ _pipe in the parameters windows of the SingularPressureLoss model (see Figure 3).

Also, the parameter K_pipe (new intermediary parameter), must be created (declared) in the main model, with [K_pipe (fixed=false, start $=1 . e 2)$ ], see Table 1.

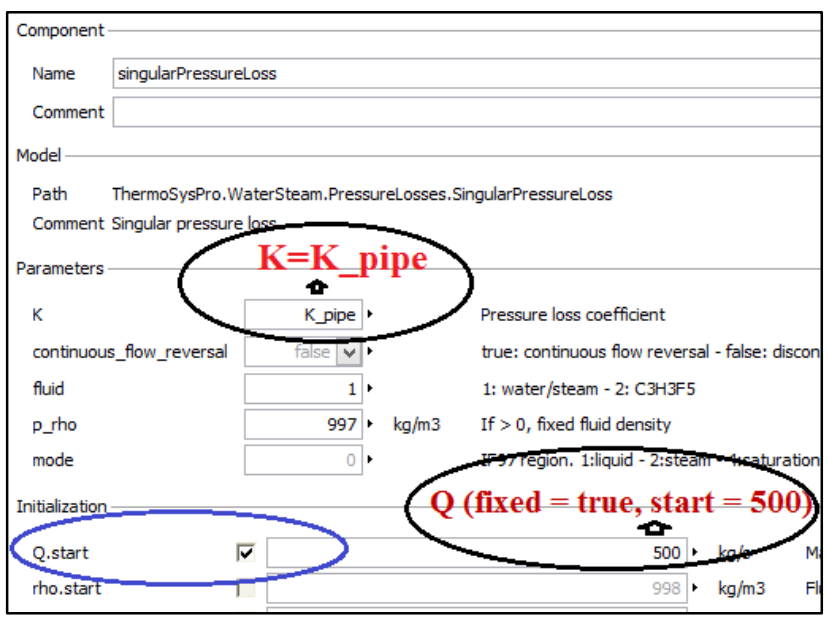

Figure 3. Data for the SingularPressureLoss model.

Table 1. The declaration of the $\mathbf{K} \_p i p e$ in the main model.

model TestSingularPressureLoss
$\quad$ parameter Real K_pipe (fixed=false,start=1.e2)
"Pressure loss coefficient";
|믐
equation

\section{Combined cycle power plant model}

The power plant model is a complete model of a real combined cycle power plant:

Gas Turbine (GT): Nominal power: $2 * 226 \mathrm{MW}$,
Steam Generator (HRSG): Thermal power: 2*360 MW,

Steam Turbine: Nominal power: 277 MW,

\section{Condenser:}

Thermal power: $428 \mathrm{MW}$.

Outlet water temperature: $305 \mathrm{~K}$

Vacuum pressure: $6100 \mathrm{~Pa}$.

\subsection{Model description}

Currently, two models are used: one to simulate the power generator step reduction load (see Figure 4), the other to simulate the full GT trip (see Figure 5). In the model used to simulate the GT trip, the gas turbine is replaced by a boundary condition.

The model contains two main parts: the water/steam cycle and the flue gases subsystem. Only one train is modelled, so identical behavior is assumed for each HRSG and for each gas turbine.

\section{HRSG model:}

The model consists of 16 heat exchangers (3 evaporators, 6 economizers, 7 super-heaters), 3 evaporating loops (low, intermediate and high pressure), 3 drums, 3 steam turbine stages (HP, IP and LP), 3 pumps, 9 valves, several pressure drops, several mixers, several collectors, 1 condenser, 1 generator, several sensors, sources, sinks and the control system limited to the drums level control.

An important feature of this model is that the thermodynamic cycle is completely closed through the condenser. This is something difficult to achieve, because of the difficulty of finding the numerical balance of large closed loops.

The list of components used for the development of the HRSG model is given in Table 2.

Table 2. Library components used in the HRSG model.

\begin{tabular}{|l|l|}
\hline Type & Model name in the library \\
\hline Condenser & DynamicCondenser \\
\hline Drum & DynamicDrum \\
\hline Generator & Generator \\
\hline $\begin{array}{l}\text { Heat } \\
\text { exchanger }\end{array}$ & $\begin{array}{l}\text { DynamicExchangerWaterSteamFlue } \\
\text { Gases } \\
\text { DynamicTwoPhaseFlowPipe } \\
\text { ExchangerFlueGasesMetal } \\
\text { HeatExchangerWall }\end{array}$ \\
\hline Pipe & LumpedStraightPipe \\
\hline Pump & StaticCentrifugalPump \\
\hline $\begin{array}{l}\text { Steam } \\
\text { turbine }\end{array}$ & StodolaTurbine \\
\hline Valve & ControlValve \\
\hline
\end{tabular}




\begin{tabular}{|l|l|}
\hline $\begin{array}{l}\text { Water } \\
\text { mixer }\end{array}$ & VolumeB, VolumeC \\
\hline $\begin{array}{l}\text { Water } \\
\text { splitter }\end{array}$ & VolumeA, VolumeD \\
\hline
\end{tabular}

\section{Heat Exchanger:}

Based on first principles mass, momentum and energy balance equations, the following phenomena are represented:

- Transverse heat transfer,

- Mass accumulation,

- Thermal inertia,

- Gravity,

- Pressure drop within local flow rate.

\section{Drum and Condenser:}

Based on first principles mass and energy balance equations for water and steam, the following phenomena are represented:

- Drum level and swell and shrink phenomenon,

- Heat exchange between the steam/water and the wall,

- Heat exchange between the outside wall and the external medium.

\section{Steam turbine:}

Based on an ellipse law and an isentropic efficiency.

\section{Pump:}

Based on the characteristics curves.

\section{Pressure drop in pipes:}

Proportional to the dynamic pressure \pm the static pressure.

\section{Mixer/splitter:}

Based on the mass and energy balances for the fluid.

\section{GT model:}

The model consists of 1 compressor, 1 gas turbine, 1 combustion chamber, sources, sinks and 1 air humidity model.

The list of component models used for the development of the GT model is given in Table 3 .

Table 3. Library components used in the GT model.

\begin{tabular}{|l|l|}
\hline Type & Model name in the library \\
\hline Air humidity & AirHumidity \\
\hline Compressor & GTCompressor \\
\hline Gas turbine & CombutionTurbine \\
\hline $\begin{array}{l}\text { Combustion } \\
\text { chamber }\end{array}$ & GTCombustionChamber \\
\hline
\end{tabular}

\section{Gas turbine:}

Based on correlations for the characteristic.

\section{Compressor:}

Based on correlations for the characteristic.

\section{Combustion chamber:}

Based on first principles mass, momentum and energy balance equations. The pressure loss in the combustion chamber is taken into account.

The "CombinedCyclePowerPlant" model contains 673 component models, generating 10802 variables, 257 differentiated variables, 2752 equations and 1855 nontrivial equations.

\subsection{Data implemented in the model}

All geometrical data were provided to the model (pipes and exchangers lengths and diameters, heat transfer surfaces of exchangers, volumes ...).

The plant characteristics are given below.

\section{Gas Turbine (GT)}

Compressor compression rate: 14

Steam Generator (HRSG)

HRSG with 3 levels of pressure.

High pressure circuit at nominal power: 127 bar

Intermediate pressure circuit at nominal power: 27 bar

Low pressure circuit at nominal power: $5.0 \mathrm{bar}$

\section{Steam Turbine}

High pressure at nominal power: $124.5 \mathrm{bar}, 815 \mathrm{~K}$

Intermediate pressure at nominal power: $25.5 \mathrm{bar}, 801 \mathrm{~K}$

Low pressure at nominal power: 4.8 bar, $532 \mathrm{~K}$

\section{Condenser}

Steam flow rate: $194 \mathrm{~kg} / \mathrm{s}$

Water temperature at the inlet: $306 \mathrm{~K}$

\subsection{Model calibration}

The calibration phase consists in setting the maximum number of thermodynamic variables to known measurement values taken from on-site sensors for $100 \%$ load. This method ensures that all needed performance parameters and size characteristics can be computed. The variables imposed in the model are:

- Pressure at the outlet of the pumps,

- Pressure at the inlet of the steam turbines,

- Specific enthalpy at the inlet of the steam turbines,

- Liquid level in drums and in condenser,

- Overall heat exchangers coefficients,

- Isentropic efficiency of the compressor,

- Exhaust temperature of the gas turbine,

- ...

The main computed performance parameters are:

- The characteristics of the pumps,

- The ellipse law coefficients of the steam turbines,

- The isentropic efficiencies of the turbines,

- The CV of the valves and the valves positions (openings). 
- Heat exchangers fouling coefficients,

- Nominal isentropic efficiency of the compressor,

- Nominal isentropic efficiency of the gas turbine,

- ...

\subsection{Simulation scenarios}

For simulation runs, two scenarios were selected. The first scenario is a power generator step reduction from 100 to $50 \%$ load:

- Initial state (combined cycle): $100 \%$ load

- Final state (combined cycle): 50\% load (800 s slope).

The second scenario is a full GT trip (sudden stopping of the gas turbine):

- Initial state (GT exhaust): $894 \mathrm{~K}, 607 \mathrm{~kg} / \mathrm{s}$

- Final state (GT exhaust): $423 \mathrm{~K}, 50 \mathrm{~kg} / \mathrm{s}(600 \mathrm{~s}$ slope).

\subsection{Simulation}

Simulation runs were done using Dymola 2017 and OpenModelica 1.11.0. The simulation of the scenarios were mostly successful. However, some difficulties were encountered when simulating large transients, mainly stemming from the large size of the model:

- Poor debugging facility,

- Large number of values to be manually provided by the user for the iteration variables, for the two tools.

In particular, it has been observed that, the two tools cannot calculate the initial states, when all iterations variables are not set close to their solution values.

\subsection{Simulation results}

The model is able to compute:

- The air excess,

- The distribution of water and steam mass flow rates,

- The thermal power of heat exchangers,

- The electrical power provided by the generator,

- The pressure temperature and specific enthalpy distribution across the network,

- The drums levels and the condenser level,

- The performance parameters of all the equipments,

- The global efficiencies of the water/steam cycle and gas turbine.

The results of the simulation runs are given in Figure 6 and Figure 7. They are consistent with the engineer's expertise. The comparison between simulation results and GE (General Electric) results (FOUQUET L, 2004) for $100 \%$ load and $50 \%$ load, have shown that the Simulation results are very close to the GE values (Design results).
The computational time is faster than real time.

\subsection{Comparison between Dymola and OpenModelica}

The simulation results of OM are very close to the simulation results of Dymola. The simulation time with $\mathrm{OM}$ is between $15 \%$ and $60 \%$ times slower than the simulation time with Dymola, depending on the scenario and the tolerance (see Table 4).

Table 4. Simulation time.

\begin{tabular}{|c|c|c|c|c|}
\hline \multicolumn{5}{|c|}{ Simulation time $(\mathbf{s})$} \\
\hline & Tolérance $=0,001$ & Tolérance $=0,0001$ & Tolérance $=0,001$ & Tolérance $=0,0001$ \\
\hline $\begin{array}{c}\text { Variation de charge } \\
\text { (simulation 2500 s) }\end{array}$ & 58 & 73 & 75 & 84 \\
$\begin{array}{c}\text { Trip TAC } \\
\text { (simulation 10000 s) }\end{array}$ & 174 & 310 & 240 & 492 \\
\hline
\end{tabular}

However, OM is still 20 times faster than real time in the worst case.

\section{Conclusion}

A dynamic and rather large model of a combined cycle power plant has been developed to validate the ThermoSysPro library. This model comprises the flue gas side and the full thermo-dynamic water/steam cycle closed through the condenser. Two difficult transients were simulated with Dymola 2017and OpenModelica 1.11.0: a step reduction load of the power generator and a full gas turbine trip. The results are mostly consistent with the engineer's expertise.

Despite of some simulation difficulties because of the lack of debugging tools for Modelica models, this work shows that the library is complete and robust enough for the modelling and simulation of complex power plants with the two software.

The simulation results of OM are very close to the simulation results of Dymola. The simulation time with $\mathrm{OM}$ is slower than simulation time with Dymola, but still 20 times faster than real time.

This work shows that OpenModelica software is very satisfying for thermo-hydraulic modelling and simulation.

\section{Acknowledgements}

This work was partially supported by the OPENCPS project.

\section{References}

David F., Souyri A. and Marchais G., 'Modeling Steam Generators for Sodium Fast Reactors with Modelica', Modelica 2009 conference proceedings.

El Hefni B. and Péchiné B., 'Model driven optimization of biomass CHP plant design', Mathmod conference 2009, Vienna, Austria. 
El Hefni B. 'Dynamic modeling of concentrated solar power plants with the ThermoSysPro Library (Parabolic Trough collectors, Fresnel reflector and Solar-Hybrid)', SolarPaces 2013, Elsevier's Energy Procedia,

El Hefni B., 'Modèle physique/neutronique en Modelica d'un outil d'aide au pilotage du transitoire sensible de montée en puissance à $3 \% \mathrm{Pn} / \mathrm{h}$ après rechargement. Maquettage d'un outil d'aide au pilotage sous Excel/VB', LMCS 2011.

El Hefni B. and Soler R. 'Dynamic multi-configuration model of a $145 \mathrm{MWe}$ concentrated solar power plant with the ThermoSysPro library (tower receiver, molten salt storage and steam generator)', SolarPaces 2014, Elsevier's Energy Procedia.

Qing Li, Fengwu Bai, Bei Yang, Baligh El Hefni and Sijie Liu, 'Dynamic simulation and experimental validation of Open Air Receiver and Thermal Energy Storage systems in solar thermal power plant', SWC 2015 en Koré 2015.
Liua S.J., Faille D., Fouquet M., El Hefni B., Wangc Y., Zhang J.B., Wang Z.F.,.Chen G.F and Soler R., 'Dynamic simulation of a 1 MWe CSP tower plant with two-level thermal storage implemented with control system', SolarPaces 2014, Elsevier's Energy Procedia.

El Hefni B., Bouskela D. Lebreton G., 'Dynamic modelling of a combined cycle power plant with ThermoSysPro', MODELICA 2011 conference.

FOUQUET L, EDF Pôle Industrie, CNET: Y.PM.X.000.PPPP.00.X.0872: PhuMy2.2: Overall plant operation description, 2004.

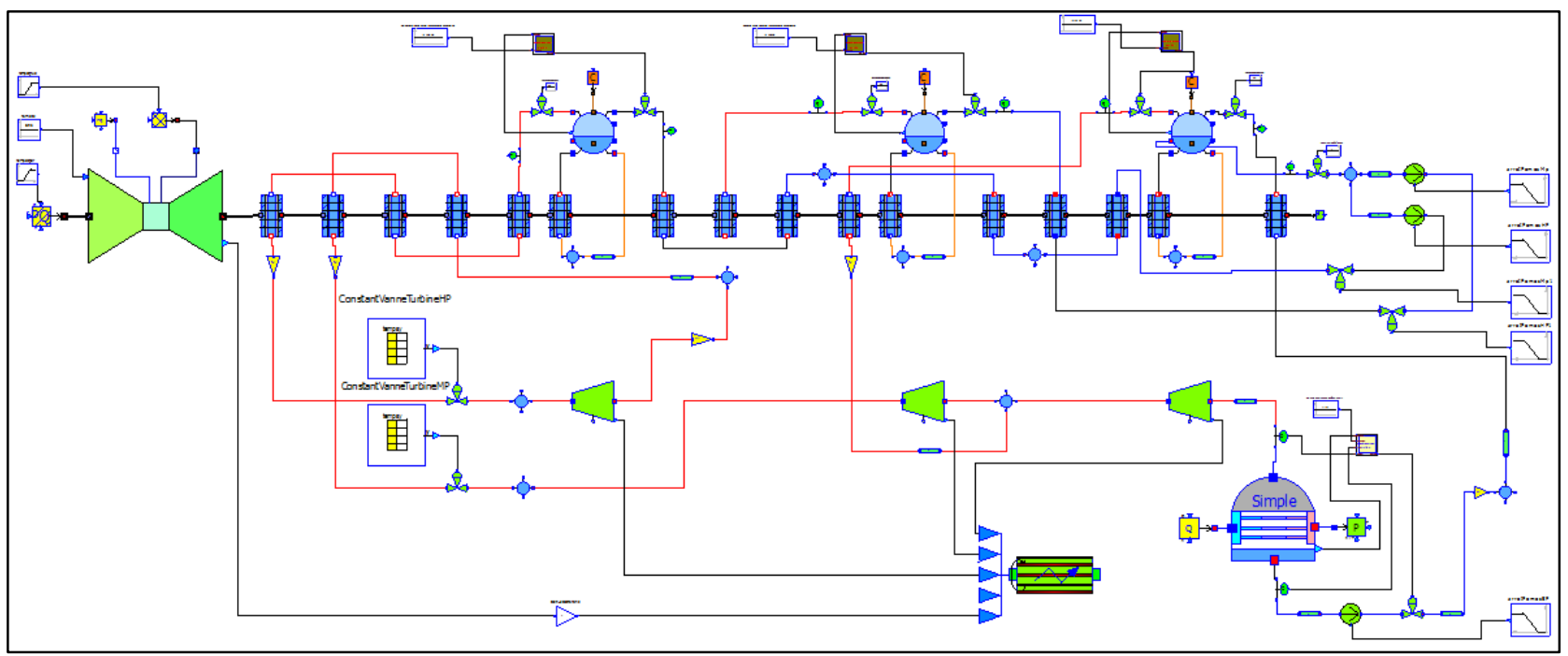

Figure 4. Model of the combined cycle power plant used for the power generator step reduction load.

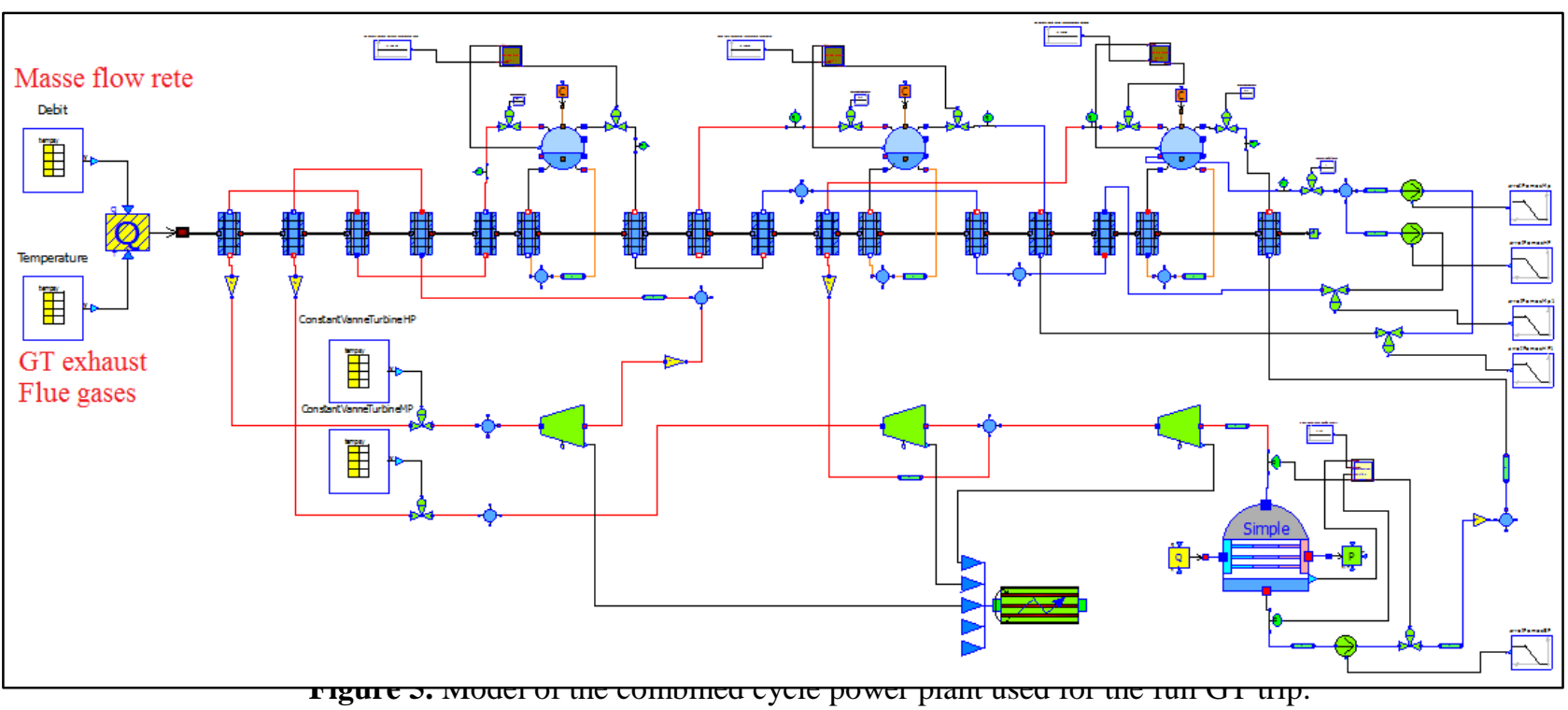



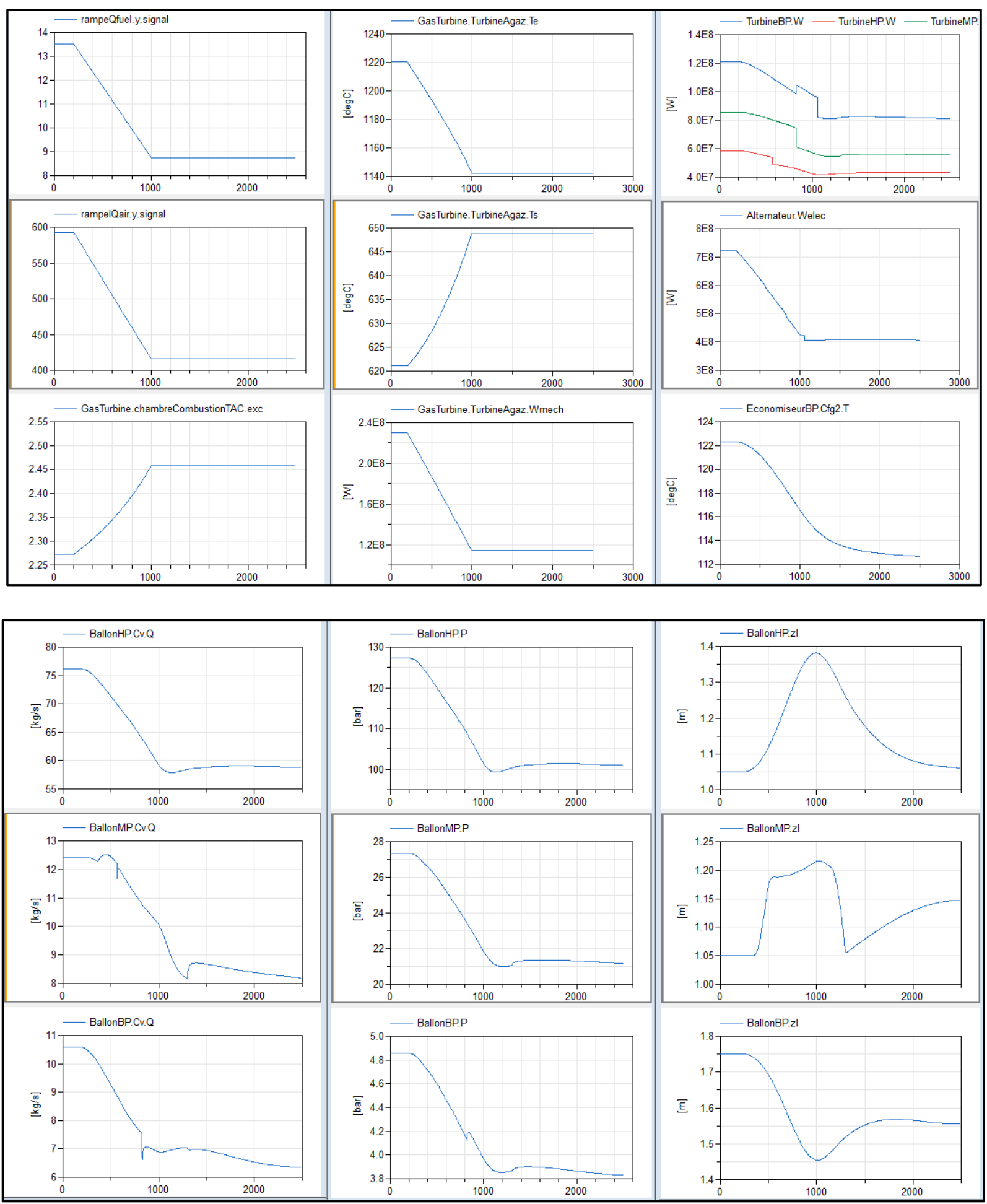

Figure 6. Power generator step reduction simulation (-50\%): natural gas mass flow rate, air mass flow rate, excess air temperature at the inlet of the combustion turbine, exhaust temperature (gas turbine), mechanical power of the combustion turbine, mechanical power produced by each steam turbine, generator power, HRSG temperature at the outlet, steam mass flow rate produced in each drum, the drums pressure, and the drums level. 
Modeling and simulation of complex ThermoSysPro model with OpenModelica - Dynamic Modeling of a combined cycle power plant
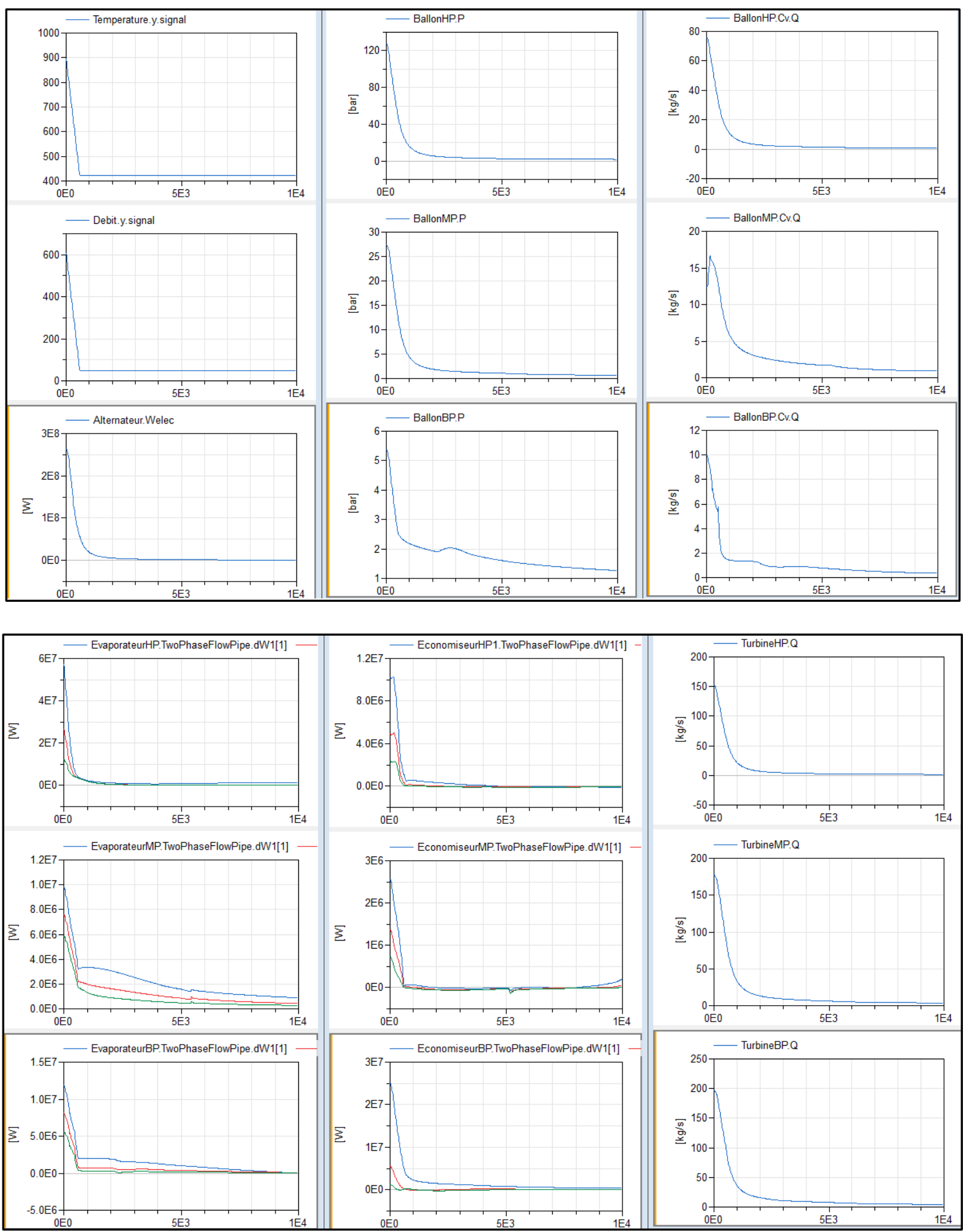

Figure 7. Gas turbine trip simulation: flue gases temperature at the inlet of the HRSG, flue gases mass flow rate at the inlet of the HRSG, generator power, the drums pressure, steam mass flow rate produced in each drum, thermal power produced in each heat exchanger (Evaporators HP, IP, LP and economizers HP, IP, LP), and steam mass flow rate in each steam turbine. 